\title{
2. Participation structure in fictional discourse: Authors, scriptwriters, audiences and characters
}

\author{
Thomas C. Messerli
}

\begin{abstract}
This chapter provides an overview of the participation structure in fictional discourse by discussing the relevant theoretical participation frameworks. The main focus is on the discourse of film and television, which is discussed in-depth, before the participation structures of literary fiction and drama are also addressed. The discussion highlights the participant roles each of the models describes for authors/producers, characters, and particularly for recipients/readers, which are given most focus in pragmatic research. One of the key differences between different frameworks has been the conceptualization of recipients/readers as either ratified participants or unratified overhearers. The chapter explains the terms as they are used by Goffman $(1976,1979)$ as well as the different positions that the respective theoretical approaches adopt.
\end{abstract}

\section{Introduction}

Fiction, as it is understood in this handbook, is far from being a monolithic entity. The first chapter pointed to the fuzzy boundaries between the non-fictional and the fictional, and it included as part of fictional language not only traditional written genres, such as the novel, but also drama and telecinematic discourse. ${ }^{1}$ This points to a heterogeneity of fictional texts and fictional language, and to variation in terms of production and reception processes. Writing and reading a novel, for instance, are conceivably different from staging and attending a play, or from writing/directing and viewing a film or television series. Accordingly, it may be necessary not to speak of a singular participation structure in fictional discourse, but of a plurality of structures or frameworks that will establish the participant roles of either authors and readers, of playwrights and theatregoers, or of scriptwriters/ directors and cinematic/televisual audiences.

Studying the relevant literature in such fields as stylistics, literary pragmatics or the pragmatic literature on drama and on telecinematic discourse, one will indeed find a clear separation between different fictional domains - with participation in written fiction largely confined to literary pragmatics and stylistics, and that

Telecinematic discourse is the umbrella term used by Piazza, Bednarek and Rossi (2011) to refer to both the discourses of cinema and fictional television. 
of drama and telecinematic discourse to their respective subfields in pragmatics. A first observation about the current state of the literature on fictional participation is then that no general theory of fictional participation that would give equal weight to fictional works in drama, film and literature has been put forward to this date.

Despite the differences between the various subcategories of fiction and despite the absence of a general theory of participation in fiction, it is worthwhile to consider the commonalities, which include the fact that any work of fiction will be based on some form of creative process that leads to the production of a fictional artefact, and that this artefact will be received in some way by one or several recipients. Moreover, these processes will lead to a form of mediated communication between creators and recipients, in which meaning-making and understanding processes are anchored on the cultural artefact.

From a pragmatic point of view, this form of communication needs to be understood as a type of language use that takes place in a specific setting and entails specific relationships between all those participants that it involves. Describing the participation structure of fiction thus means defining those relationships between participants - a task which is complicated by the fact that the fictional artefact itself contains further embedded acts of communication. These communicative acts within fiction are performed by fictional participants, the characters. An overview of the participation structures in fiction then needs to include the role of characters as well as their relationship to the relevant participants outside the fictional artefact.

In order to provide such an overview of participant roles and relationships between participants in fiction, I will return to the particular participation structures of one of the subcategories of fiction, viz. telecinematic discourse. This is necessary first of all, because, as already mentioned, the relevant literature almost invariably focuses on one specific type of fictional data and thus also on a particular structure of participation. It is also preferable because choosing the particular as a starting point allows the inclusion of examples from fictional data.

Rather than starting with an abstract conceptualization of the participation structure(s) in fiction, I will thus turn to an example from telecinematic discourse, which is the type of fictional discourse on which this chapter lays its main focus. This example will be used to illustrate the different theoretical approaches that can be taken towards the participants on- and off-screen. It will be instrumental in pinpointing the characteristic features of telecinematic participation, but it will also be described based on the assumption that the telecinematic participation framework is similar to participation structures in other fictional settings. While the analysis of Example 1 in Section 2 takes place specifically on an extract from telecinematic discourse, I will thus assume that very similar observations could be made about dramatic and literary discourse. However, an important subsequent step will be to describe the actual similarities and differences between different fictional discourses, which is the subject of the main Section 3, in which several 
participation models for telecinematic discourse are discussed, as well as of Section 4 , which provides a brief overview of participation in dramatic discourse (4.1) and in literary fiction (4.2).

\section{Fictional characters and Goffman's (1979) participation framework}

\subsection{A fictional conversation in the US sitcom Seinfeld (1989-1998)}

As a starting point for the discussion of the interaction of fictional characters, I will use a short scene from the well-known US American sitcom Seinfeld (NBC 1989-1998). Representing a dialogue between two of the main characters of a television series, it is both simple in its setup and thus accessible even to those unfamiliar with the specific scene or even Seinfeld at large, and in many ways typical as far as fictional interactions and their reading by audiences are concerned. The extract - represented here by a transcription of the broadcast (Example 1) - is taken from the television series' pilot, with the title "The Seinfeld Chronicles". In order to set up the interaction in this example, I will provide some context about some of the participants and the communicative setting. Although the extract is situated at the beginning of the very first episode, it needs to be mentioned that a large proportion of the contemporary US American audience will have been familiar with the main actor, Jerry Seinfeld, who was already a well-known stand-up comedian and a regular guest on late night television. In the sitcom, which uses his last name as the title of the series, Jerry Seinfeld plays a fictional version of himself. Prior to the excerpt presented here, the prologue of the episode showed him as a stand-up comedian in a comedy club, performing a routine about going out. Now he and his friend George are sitting in a coffee shop somewhere in New York, and they are having a conversation over coffee. After a few turns, a waitress, Claire, approaches the table and has a brief conversation with George.

The detailed transcription conventions are included as part of the appendix to this chapter, but to facilitate the reading of the example, a few explanations need to be added: The numbering refers to camera shots (sequences of film between cuts); the second column from the right transcribes the verbal interaction as well as some of the more significant bodily gestures; and the right most column serves as a short description of the visible communicative setting (mise-en-scène). For the sake of readability, the laugh track, i.e. the recorded audience laughter that forms part of the broadcast, was not transcribed. 
(1) “The Seinfeld Chronicles”, Seinfeld (NBC, 1989-1998)
Shot Speaker Dialogue/Gestures
1 Jerry See now to me that button is in the worst possi- ble spot.

2

3

4

$=$ Look at it, $=$

+-- left hand points at George---+

$=$ it's too high! It's in $\uparrow$ no-man's land. You look like you live with your mother!

George Are you through?

$\&$-turns both palms upwards-\&

5 Jerry You do of course $=$

+-open hand gesture--+

$=$ try on when you buy?

6 George Yes! It was purple! I liked it! \&-turns palms upwards-\&

I don't actually recall considering the button.

\&--both hands point forward-\&

7 Jerry Oh, you don't reca::l1?
Shot description

Ext. coffee shop, the camera zooms in towards the coffee shop.

Fade to interior of a coffee shop. There is a round table at the front of the picture, Jerry is sitting on the right, looking towards George, who is sitting on the left. Both are visible from their knees on upwards (medium shot), their bodies are positioned at an angle. In the background, other customers are sitting at tables, and Claire, the waitress, is serving coffee.

On "Look", the scene cuts to a frontal medium close-up of George, Jerry's hand gesture is at the front of the picture.

On "It's too" cut back to medium shot of Jerry and George (same as 2).

Frontal medium close-up of Jerry.

Frontal medium close-up of George.

Frontal medium close-up of Jerry. 
8 George Ehh, no, ehh not at this time. $\&$-uses pen like a microphone $-\&$

9 Jerry

Well, Senator, I'd just like to know what you knew and when you knew it. $=$

Claire $=$ Mr. Seinfeld. (.) Mr. Costanza \&-covers cup with hand---->

George Are you sure this is decaf? Where's the orange

indicator?

----------\&

Claire It's missing.

10

11

12 Jerry Can you relax?

+-------open hand gesture--+

It's a cup of coffee.

+---both palms upwards--+

Claire's a professional waitress. $=$

13 Claire Trust me, George. No one has any interest in seeing you on caffeine.

14

15

$\uparrow$ right. Decaf $\uparrow$ left, regular $\uparrow$ right.” It's ve:ry

---left and right hand------------------ $\S$

cha:llenging work.
Frontal medium

close-up of George.

Medium shot of Jerry

and George. Claire

approaches the table

from the background,

between George and

Jerry, at the centre of

the picture.

Claire pours coffee

into Jerry's cup with

her right hand, then

tries to poor coffee into

George's cup with her

right hand.

$$
\S \text {--alternates raising--> close-up of Claire. }
$$

Frontal medium

close-up of George.

Frontal medium

close-up of Jerry.

Medium shot of

George, Jerry and

Claire.

Frontal medium

close-up of Jerry.

Frontal medium

close-up of George. He

smiles.

+ Jerry

\& George

$\S$ Claire 
One first way of examining the multimodal interactions between the characters is to take a naïve stance and understand it as represented dialogue. This will be done here in order to both introduce and contextualize the example that will be used throughout the chapter, as well as to briefly outline Goffman's (1979) participation framework, on which most theoretical approaches to fictional participation are based (see discussion of individual models in Section 3). I will thus assume the non-expert position of the television audience that watches this first episode and approach the interaction in this scene as if it were a one-to-one representation of an interaction that could take place in any non-fictional coffee shop in New York City.

From this point of view, the main focus will likely be on the interaction between the two main characters, Jerry Seinfeld and George Costanza, and from shot 9 onwards also on the waitress Claire, who takes the floor. In the first turn (shots 1 to 4) for instance, Jerry makes a comment about the second button on George's shirt, while other guests in the coffee shop are drinking their coffees and the waitress in the background is refilling a customer's cup. Looking through the television set into that coffee shop and turning a blind eye to whatever context there may be outside of the fictional world in which the interaction takes place, it is a simple task to identify some of the participant roles that are represented in this turn: the speaker Jerry; the addressee George; and those uninvolved in the ongoing interaction in the foreground. Accordingly, one may start by simply applying the tools of a theoretical framework for face-to-face interaction to the conversation between Jerry and George in order to describe the communicative setting of this example of fictional discourse.

Even from a naïve perspective that leaves away the roles of those involved in TV production and reception, a discussion of the participation structure within the represented coffee shop will have to take note of the fact that George and Jerry are not alone. Therefore, a theoretical approach that goes beyond a purely dyadic view of talk will be necessary in order to arrive at a full picture of the communicative setting, which manages to also include what role the characters in the background may play in the way the interaction in the foreground takes place.

\subsection{Goffman's (1979) participation framework}

One of the main foci of Goffman's $(1976,1979)$ influential work is to go beyond a traditional analysis of talk which is limited to two participants and cannot successfully describe the workings of all those conversational encounters where three or more people are present. In earlier work, Goffman (1967) already describes the ratification processes between speakers and listeners and acknowledges the differences between ratified and unratified participants of talk (see footnote 24 in Goffman 1967: 34), and he explains in more detail the different types of ratified and unratified listeners in Goffman (1976). But he only brings forward his notion 
of participation framework and a clear description of the different participation roles involved in a typical communicative setting in his essay on footing (Goffman 1979). There, it becomes clear how conversation between ratified participants is influenced by those around it who are listening in or looking on. I will return to the button remark in Example 1 to illustrate the framework that Goffman envisions.

Apart from the speaker, Jerry, and the addressee, George, who are the ratified participants here, there are a number of customers as well as the waitress present in the scene. In Goffman's terms, these unratified participants may either be eavesdroppers, overhearers, or bystanders. Assuming that they remain unnoticed by the ratified participants, they are either eavesdroppers, if they intentionally listen in on the conversation, or overhearers, if "the opportunity has unintentionally and inadvertently come about" (Goffman 1979: 8). They are bystanders, on the other hand, if George and Jerry are aware of their presence. Even as acknowledged bystanders, the characters in the background are not directly involved in the actual conversation between ratified participants, but as Goffman (1979: 10) points out, they will nonetheless be influential, because: "speakers will modify how they speak, if not what they say, by virtue of conducting their talk in visual and aural range of nonparticipants". In other words, the fact that George and Jerry's conversation takes place in a public place (the coffee shop) and that it is at least potentially overheard by the other customers and the waitress, will influence the linguistic choices of the two ratified participants and the way the conversation evolves.

Insofar as characters, places, events etc. are understood as representations of real people, real places and real events, Goffman's participation framework for non-fictional face-to-face interaction can thus be used to describe the participation roles of the fictional participants, which is done by simply mapping each fictional character role to the non-fictional referent it represents. ${ }^{2}$ Essentially, this amounts to the observer taking the position of a character that shares the space of the other fictional characters and operates entirely oblivious to the fictionality and constructedness of the fictional world.

Arguing from this position, an interactional analysis of the scene may focus on a range of features that may strike the researcher as different from other interactions in coffee shops. ${ }^{3}$ For instance, turn-taking happens in such a fashion that there are no overlaps; there are no false starts and turns almost exclusively consist of syntactically well-formed sentences; there is only a single hesitation marker (George in shot 8); and the interlocutors show a propensity for rhythmically stressing several words per intonation unit and accentuating those stresses with the help

2 Understanding fictional characters as if they were real-life people is what Culpeper (2001) calls the humanising approach.

3 The extract here can be compared, for instance, with the examples in Sacks, Schegloff and Jefferson (1974). 
of hand gestures. In other words, the interaction can be described as exceedingly orderly and thus different from what may be expected when analysing spoken face-to-face interaction in an informal setting (see Bublitz, Ch. 8 on features of orality). Here at the latest, when trying to explain this orderliness of the displayed turn-taking, the naïve position of audience-as-character will no longer be sufficient to explain the interaction - it becomes necessary to look past the represented fictional situation and include the telecinematic context in which the interaction takes place.

The most obvious answer to the question why an analysis of the spoken interaction in Seinfeld is markedly different from spontaneous face-to-face interaction is then quite simply that it is not spontaneous interaction. While circumstantial evidence within the fictional world points to an informal talk between friends in a coffee shop, there is also clear evidence that this is taking place within a fictional television series - for instance in the form of the conventional metacommunicative cues that are available to audiences in TV guides, their own viewing context or the cues within the broadcast itself (see Brock 2009). It is thus safe to assume that most audiences of Seinfeld will share the knowledge that the representation on screen is not the product of the surreptitious recording of an actual conversation between Jerry Seinfeld and Jason Alexander (the actor who plays George Costanza in the sitcom), but that there is some form of TV-making apparatus at work, which involves writers, producers, directors, actors, as well as operators of cameras, sound, lighting and other telecinematic parameters. Whereas spontaneous spoken interaction involves negotiating turn transitions between interlocutors as well as thinking and speech production processes in each participant, such negotiating and processing is absent or greatly reduced in the case of fictional interactions, because the interaction is scripted and thus prepared not only in terms of the formulation of individual utterances, but also in terms of the turn-taking between interlocutors.

This distinction can best be clarified with the help of the concepts of animator, author, and principal (Goffman 1979), i.e. the differentiation of three roles involved on the speaker-side of any interaction. While the animator is the one vocalizing the utterance, the author formulates it, and the principal is the one whose set of beliefs are being expressed in language (Goffman 1979: 16-17). All three roles are performed by the speaker in spontaneous spoken interaction, who has something she means to express in mind, formulates it and utters it. In fictional discourse, however, these roles are separated: The actor Jerry Seinfeld vocalizes what the writing staff of Seinfeld formulated and the creators/producers of the sitcom meant to convey.

This is to say that the synchronous interaction between Jerry and George in Example 1 is in fact part of a larger communicative context of TV-making. The interaction on the surface depends on communicative processes on another level, which include the collective of those involved in making the fictional artefact - in 
this case the sitcom - as well as those involved on the recipient-side, i.e. the audiences or readers that are observing the fictional interaction. ${ }^{4}$

\subsection{Communicative levels}

Within pragmatics as well as media and television studies, there is wide agreement that this duality of levels needs to be taken into account when approaching the communicative setting of telecinematic discourse and of mass media communication (see Chovanec and Dynel 2015: 5), as well as that of other forms of fiction. The levels in fictional discourses have been discussed using different terminology - and broadly speaking two different spatial metaphors have been brought forward to conceptualize their relative position within the communicative setting. The first one understands fictional interaction as embedded in communication between authors/producers and audiences; the second one places inter-character talk on a layer on top of the primary layer between the producers and recipients of the artefact. Despite the spatial difference between the two understandings both conceptualizations are similar in that they highlight a dependency of the fictional level on the primary communication between authors/producers and audiences.

Examples following the first paradigm include Short (1981), who speaks of dramatic discourse in terms of embeddedness; Burger (Burger 1984, 1991; Burger and Luginbühl 2014), who follows the same notion of embeddedness when he situates mass media communication in different communicative circles (Kommunikationskreise); and Androutsopoulos (2012: 140-141), who uses the term double framework - in explicit analogy to models from literary studies - and states that "communication in the fictional world is embedded into the communicative relation between 'author' (or 'producer') and 'reader' (or 'audience')".

Essential to the second paradigm is Clark (1996: 353), who regards as a commonality of the language of "novels, plays, movies, stories, and jokes, as well as teasing, irony, sarcasm, overstatement, and understatement" that they involve a form of joint pretence between participants, which opens up a second domain or layer of action. Clark emphasizes the clear hierarchy between the layers, with layer 2 being dependent on layer 1 . The model visualizes the fictional layer (as well as other dependent layers) as a stage, and layer 1, on which it rests, as a representation of the "actual world" (Clark 1996: 16).

The notion of layers is taken up by Kozloff (2000) and also by Bubel (2006, 2008), who includes Short's $(1981,1989)$ embeddedness and Burger's (1984, 1991) communicative circles, but most heavily relies on Clark's (1996) conceptualization for her own model of screen-to-face communication. Bednarek (2010)

4 The different conceptions of the role of the audience/reader will be discussed in Section 3 . 
in turn discusses television language based on Bubel's model, whereas Piazza, Bednarek and Rossi (2011) only implicitly follow the same spatial hierarchy when they speak of a double plane of communication. Desilla (2012), following Vanoye (1985), regards the communication between authors/producers and audiences as happening on a vertical level, which is opposed to the horizontal level of fictional interactions. Dynel (2011) and Brock (2015) both develop their own models and visualizations and speak more generally of communicative levels (see the discussion in Sections 3.3 and 3.4).

Despite the range of different terms and different spatial metaphors employed in the theoretical works mentioned here, there will be a clear consensus when analysing Example 1 from any of the theoretical vantage points that the interaction between Jerry and George is in some way dependent on - i.e. it is embedded in or rests upon - another level of communication between authors/producers and television audiences. Furthermore, all scholars represented here will agree that this dependency of fictional communication will greatly affect the form Jerry and George's interaction takes - both with regard to the linguistic realization of the individual utterances and the interactional organisation of the conversation between the two characters.

There are, however, substantial differences with regard to how exactly the roles of authors/producers and audiences are conceptualized, and how the meaning-making and understanding processes on both sides are theorized in the different approaches.

\section{The participation framework of telecinematic discourse}

Having established the Goffmanian participation framework as well as the multilayeredness of telecinematic discourse, and by extension of fictional discourse at large, this section will discuss four theoretical approaches to a specifically telecinematic participation framework as they have been put forward in the last decade. All of these models focus on the audience and their understanding processes, while the actual production of the telecinematic artefact is only marginally represented. However, as the chronological discussion will show, a tendency towards a more fine-grained look at production-side processes can be observed.

The first theoretical framework discussed here is the one put forward by Bubel $(2006,2008)$, which is commonly referred to in connection with the viewer-as-overhearer paradigm. Bubel adopts the notion that audiences are overhearers from Kozloff (2000), and the same view is also shared by Richardson (2010). Section 3.2. will discuss Bednarek's (2010) additions and specifications to Bubel's model. Dynel's (2011) viewer-as-ratified hearer approach will be discussed in Section 3.3, and finally Brock's (2015) comparison of different comedy genres will be presented in Section 3.4. 


\subsection{Participation in Bubel $(2006,2008)$}

The central notion in Bubel's $(2006,2008)$ participation model of telecinematic discourse is that audiences have to be conceptualized as overhearers - an understanding which had already been put forward in film studies by Kozloff (2000). Like all other theoretical approaches presented here, she is indebted to Goffman, but her model is notable for a more in-depth integration of cognitive pragmatics and specifically for the inclusion of the audience's thinking processes. In order to characterize Bubel's understanding of telecinematic discourse, it is thus best to briefly look back to Goffman (1979) and to include the elaboration on the Goffmanian framework by Clark and Schaefer (1992) and Clark (1996), which will illuminate how Bubel transfers the relevant aspects of participation to the telecinematic domain.

As Bubel (2008: 62) acknowledges, Goffman himself already addresses the role of theatre as well as radio and TV broadcast audiences, and he positions them as different from participants and non-participants in ordinary face-to-face conversation: Audiences for Goffman are participants in stage events rather than in talk, and he explains that there is a need for participation frameworks specific to theatre, radio and television (Goffman, 1979: 12-14). Bubel, however, does not focus on Goffman's notion of audience, and instead is interested in what the communication situations of the everyday overhearer and that of the television or film audience have in common:

The cognitive processes going on in the spectator while he or she is listening to film dialogue are generally parallel to those that occur in everyday life, when we take on the role of an overhearer, whether or not the conversation we are overhearing is meant to be heard by us, and whether or not the conversationalists are aware of our listening in.

(Bubel 2008: 61)

Bubel's discussion of spectators first of all follows Clark (1996) in using a wider definition of overhearer, which encompasses all three types of non-ratified listeners mentioned by Goffman (1979) and envisions overhearer roles on a continuum between bystanders and eavesdroppers. Irrespective of such terminological differences to Goffman, Bubel's (2008) model for what she terms screen-to-face discourse positions audience members as unratified participants, who are thus outside of the main communication situation and have no "rights or responsibilities" (Bubel 2008: 64; see also Clark 1996: 14) in the on-going interaction.

For Bubel (2008: 64-65), this lack of rights and responsibilities compared to ratified participants leads to a disadvantage for overhearers in general, and telecinematic overhearers in particular, when they try to understand conversations on screen. Bubel (2008: 64) specifies first of all that spectators have limited personal common ground with the characters. Using Clark's (1996) terms she states that characters and audience have few shared experiences due to the limited time of interacting with each other (the length of the film or TV series). Moreover, the experiences that 
they share are one-sided, with audiences gathering knowledge about characters, but not vice versa. The same one-sidedness of the shared experiences leads to an inability on the side of the audience to play an active part in negotiating meaning (Bubel 2008: 64). These disadvantages serve as a stepping-stone to convincingly explain the motivation behind what Bubel terms overhearer design, which is how she labels the version of Sacks, Schegloff and Jefferson's (1974) recipient design she uses in her model. This means that fictional conversations do not just occur of their own accord, but are written with a television audience in mind.

On the one hand, Bubel (2008: 62) thus acknowledges that spectators strictly speaking cannot be regarded as eavesdroppers or bystanders, because - as Short (1989: 149 quoted in Bubel 2008: 62) points out - "the situation is arranged to be overheard on purpose". On the other hand, she lists two reasons for insisting on referring to them as overhearers. The first one is the similarity she sees between television audiences and those overhearers of face-to-face conversations that are not only acknowledged by the ratified participants, but who are meant "to glean certain information from what [the conversationalists] are saying" (Bubel 2008: 62 ). The second reason has to do with the separate layer of action on which the fictional interactions take place. Just as this layer is conventionally sealed off from the interaction between authors/producers and audiences, face-to-face conversation of ratified conversationalists is equally separated from an overhearing third party (Bubel 2008: 62).

The resulting model, as it is reproduced here in Figure 1, thus marries two at least seemingly contrary positions of the audience, which has to be understood as both the target of the author/producer's overhearer design, and also as the hermetically sealed off and disadvantaged overhearer listening in on inter-character conversations. For this combination of different audience roles, Bubel leans on Clark and Schaefer's (1992) elaboration on Goffman's (1979) notion of overhearer. Their discussion of attitudes towards overhearers identifies disclosure as one possible attitude, which means that "the conversationalists want the overhearer to gather certain information from the conversation, providing the overhearer with enough evidence to make correct conjectures" (Bubel 2006: 55). This is central for Bubel because it combines an intention to be understood with the notion of overhearing.

As Figure 1 illustrates, the fictional verbal interaction at the centre of the framework is designed by the film production crew with overhearers in mind; and film recipients use cognitive processes of conjecture to read the cues designed for them and to understand the interaction on screen "with the help of the part of their world knowledge that overlaps with the world knowledge the production team projects onto the characters" (Bubel 2008: 67). While the visualization specifically puts verbal interaction at the centre of the model, Bubel $(2006,2008)$ also explicitly includes other telecinematic sign systems, such as camera angles and the editing process as part of what is designed for the overhearing audience, but she does not further discuss such aspects of multimodality. 


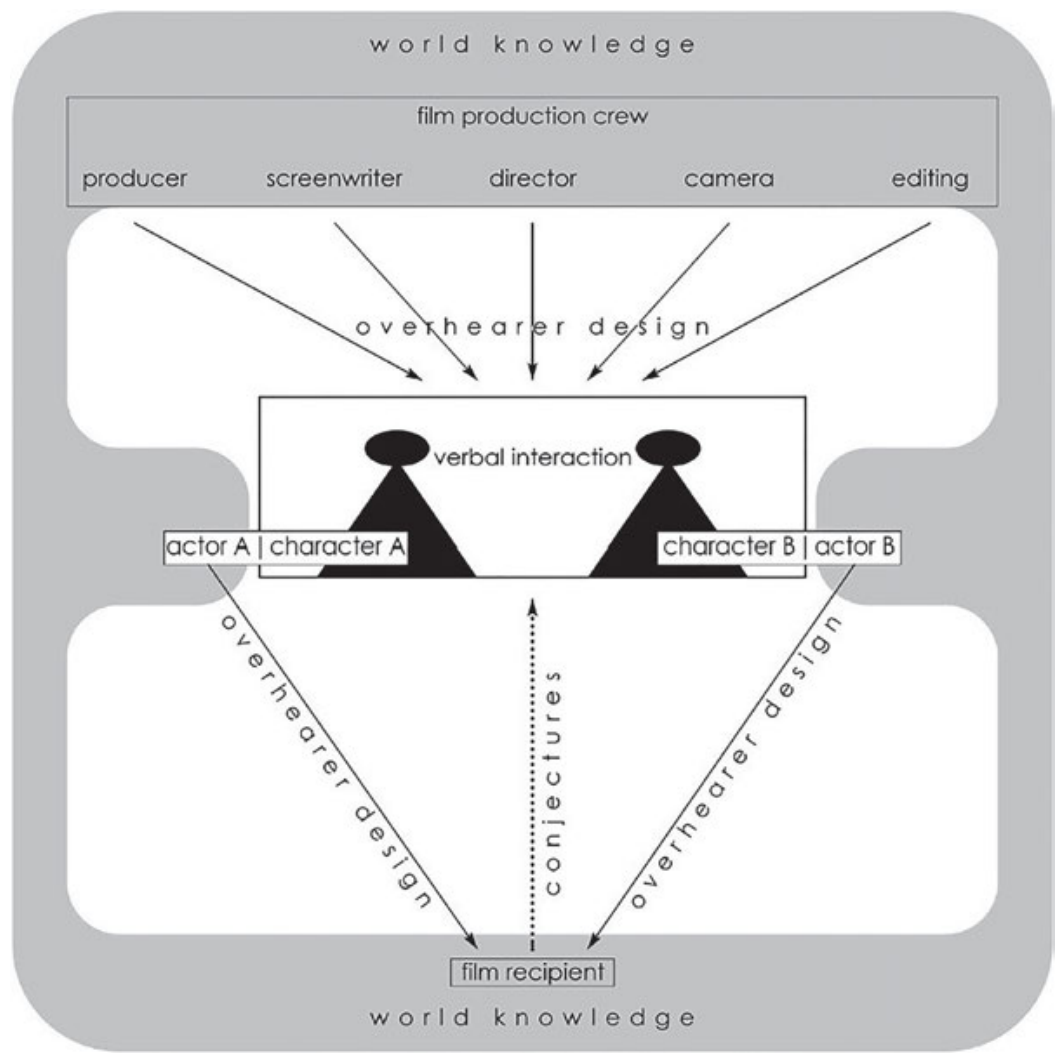

Figure 1. Participants in telecinematic discourse in Bubel (2006: 58)

Bubel $(2006,2008)$ also addresses the degree to which the audience can be said to be aware of the fictionality of the ongoing interaction. Bubel follows Clark (1996) here and adopts his binary pair of imagination and appreciation. They describe two types of cognitive processes in viewers, which take place on different layers of action. Imagination refers to Coleridge's "willing suspension of disbelief" (see e.g. Kozloff 2000: 47; Bednarek 2012: 47) - which means that audiences at least to some degree willingly pretend that the utterances and actions performed by the fictional characters are products of the actors' own will and intent rather than of the writing processes involved in film and television making. The result of this process of imagination is a key component in audiences' enjoyment of fiction: "One effect of film is that it transports the audience into the realm of the story and, doing that, evokes emotions and suspense" (Bubel 2008: 59; see also Clark 1996: 366).

In contrast, the second process of appreciation requires that audiences are aware of the constructedness of the fictional layer and enjoy the craftsmanship 
of the production-side processes that lead to its construction. In her discussion of appreciation, Bubel (2008: 60) also points to Kozloff (2000: 55-60), who highlights that characters may overtly or discretely address the viewers and thus break the illusion, which is the case for instance in moralizing speeches, allegorical elements and authorial messages. In other words, while imagination immerses audiences in the topmost fictional layer, appreciation draws attention to those underlying layers necessary for its construction. The duality in the different notions of overhearer as outlined above thus finds its equivalence in an oscillation between two very different viewing processes that, in Bubel's view can both be in operation at different moments in the telecinematic viewing situation.

Applying Bubel's model to Example 1, Jerry and George can be said to address each other, and to be doing so in a fashion that invites audiences to read specific cues and make inferences based on them and on their world knowledge. Audiences "retrieve stored cognitive models or frames that are prompted by the utterance" (Bubel 2008: 63), which in this case will include information about interactions among friends, events that happen in coffee shops, but also knowledge about film and television in general and sitcoms in particular. The fact that the cues designed by the production crew guide the understanding processes of the audience gives a plausible explanation, for instance, for the fact that the waitress in shot 9 addresses the customers Jerry and George with their full last names, and in shot 13 refers to George with his first name. Jerry similarly uses the first name of the waitress in shot 12, when he mentions that "Claire is a professional waitress". Irrespective of whether or not such usage of first and last names may be odd in non-fictional coffee shops, Bubel's approach will highlight that this information neatly complements prior knowledge of the television audience, who - as stated in Section 2.1 - are likely to already know the main actor/character Jerry Seinfeld, but will have no knowledge of the names of any of the other characters. Apart from whatever motivation there may be within the fictional setting for the characters to use each other's names, this information is quite clearly written by the scriptwriters for the benefit of the television audiences. Later in this episode, and in subsequent episodes, knowledge of these character names can be assumed to be part of the production crew's and the regular audience's common ground.

The fact that the camera in shot 1 shows the exterior of a coffee shop can be understood in similar ways. Based on the conventions of continuity editing, this exterior shot can be inferred to be of the same coffee shop in which the verbal interaction takes place a moment later. Thus, the telecinematic signals indicate the location of the subsequent interaction to the television audience - notably in absence of any characters in the initial exterior shot. A further case in point is the positioning of the characters which sit at an angle of approximately 45 degrees, which is to say that their upper bodies can still be said to face each other, while also being pointed at the camera. The montage is done in such a fashion that the speaker is always optimally visible, as can be seen for instance in the medium 
close-ups in 5 and 6 - the same goes for the audibility of their utterances. In short, the entire telecinematic apparatus is employed in such a fashion that audiences are in the best possible position to overhear Jerry and George's talk and to arrive at the understanding that the production crew envisioned.

\subsection{Participation in Bednarek (2010)}

Bednarek's (2010) contribution to research on telecinematic discourse is substantial in a range of aspects, which include work on characterization and the use of corpus linguistic methods on telecinematic data (see also Bednarek 2012). This chapter's discussion of her view on participation structure will be kept short, however, since she makes use of Bubel's $(2006,2008)$ model in her work rather than developing a participation framework of her own. Nevertheless, her discussion of Bubel's $(2006,2008)$ model is worth including here because it specifies a number of aspects that were only mentioned in passing in Bubel's discussion. Two of these aspects are highlighted here.

The first aspect that needs to be mentioned is the distinction between target audience and actual audience, which - as Bednarek (2010: 17) states - is only implied in Bubel's $(2006,2008)$ model. Bednarek illustrates how target audiences are being construed not only by the film or the television series itself, but also by other texts, such as those present on DVD cases. In this regard, she opts for a stronger focus on production-side processes than Bubel $(2006,2008)$, and she also takes into account a larger context of telecinematic production and reception, which includes commercial factors. On the side of television and film production this means that creative agents can be differentiated from commercial agents; on the side of the reception, target audiences can be regarded as a commodity for advertisers (Bednarek 2010: 17).

Bednarek (2010) makes explicit the difference between target and actual audience, and she describes in some detail how target audiences are construed in televisual artefacts as well as in and by ancillary products. She is less specific about actual audiences, which fall outside the scope of her empirical research on Gilmore Girls (The WB television network 2000-2007). That individual audience members view and understand telecinematic discourse differently is addressed, however, when Bednarek (2010: 214-220) discusses the relationship between the ideologies manifest in the artefact and the audience. Here, she relies on Hall's (1994: 209-211) distinction of three different viewer positions when decoding meaning in television discourse (Bednarek 2010: 217). Hall (1994: 209) offers a "hypothetical analysis of some possible decoding positions", which distinguishes (1) a dominant-hegemonic from (2) a negotiated and (3) an oppositional position. While the first, ideal-typical case has audiences "decode[] the message in terms of the reference code in which it has been encoded" (Hall 1994: 209), the third, oppositional position suggests that audiences may decode meaning completely on their 
own terms and thus reject the dominant reading (Hall 1994: 211). Between the two poles, the second, negotiated position partly accepts the dominant framework for decoding the message, but "contains a mixture of adaptive and oppositional elements" (Hall 1994: 210).

In transferring Hall's viewer positions to the reception processes of the audiences of fictional film and television, Bednarek (2010: 217-218) finds that a distinction of decoding positions, as it is offered by Hall (1994), does not only relate to ideologies, but also to reading and viewing more generally: Audiences "engag[e] differently with media texts, mediating their interpretation with mental representations" (Bednarek 2010: 218). None of the extant theoretical models of participation in telecinematic discourse offer insights on audience reception based on empirical research with actual television or cinema audiences. However, Bednarek's (2010) study makes explicit the necessary distinction between target audience and actual audience and hints at the influence of the former on the production-side meaning-making processes as well as the significance of distinguishing subtypes of the latter in order to conceptualize different audience participation roles.

The second aspect on which Bednarek elaborates is that of multimodality, which again is only implied in Bubel. Bednarek (2010) distinguishes multimodality in characters, i.e. gestures, gaze, facial expressions as they are performed by the characters on the fictional layer, from multimodality in the product, which refers to "the meaning potential of the moving image itself" (Bednarek 2010: 20) and includes such aspects as camera, editing, lighting, but also different dimensions of sound. With regard to the understanding of the participation structure, Bednarek's discussion of multimodality highlights the range of communicative acts and semiotic systems that need to be taken into account as part of the communicative setting in and of fiction. As part of multimodality in character she also observes that bodily gestures of characters and actors are conflated in telecinematic discourse (Bednarek 2010: 19), which means that they simultaneously take place on the fictional layer and on the layer of production crew, recipients and actors. Whereas Bednarek (2010: 143-176) dedicates an entire chapter to multimodal performance, in which she is mostly interested in the multimodal construal of character identity, the notion of signals that take place simultaneously on several levels, and the effect of this simultaneity on audiences are not further discussed by her. This issue resurfaces in Brock (2015), however, and will be further discussed in Section 3.4.

\subsection{Participation in Dynel (2011)}

The participation structure proposed by Dynel (2011) positions itself opposite that of Bubel (2006, 2008). Dynel's (2011: 1629) aim is to "argue against the viewer-as-overhearer approach and advance a new conceptualization of the film viewer as a listener to film discourse/talk". She takes issue with the two contradictory 
audience participation roles inherent in Bubel's term of overhearer design, as they were discussed in Section 3.1 of this chapter. To reiterate, whereas the term overhearer positions the audience as unratified participants sealed off from the space in which characters interact, design suggests that the fictional interaction is aimed at and written for that same audience.

Based on a literature review of how overhearers have been understood in ordinary interaction, Dynel arrives at a general definition that defines overhearer as:

an unratified participant (rather than a non-participant) who listens to (and usually also watches) an utterance (or a turn) being performed in an ongoing interaction without the speaker's permission (and usually, but not always, the ratified hearer's/hearers' permission). (Dynel 2011: 1629)

The central aspect here is the lack of permission or, as Dynel adds, the fact that the speaker does not intend to be overheard. Based on this definition, Dynel finds the use of the term overhearers for audiences ill-advised, even though it is frequently applied to audiences of mass media (Dynel 2011: 1630). With regard to film audiences, Dynel takes into account Richardson's (2010: 60) point that film viewers can be seen as overhearers because they are usually not directly addressed, as well as Bubel's argument which has been discussed here in Section 3.1. She highlights, however, that the collective sender, the umbrella term she uses for all those involved in the production of fictional film and television, designs character dialogue specifically for the audience, and that viewers therefore need to be regarded as ratified participants in telecinematic discourse. Based on Goffman's imagined recipients and Hutchby's (2006) distributed recipients ${ }^{5}$ she proposes to refer to film and television audiences with the term recipient instead.

As can be seen in Figure 2, Dynel (2011) visualizes her understanding in the form of nested containers, with the fictional level 1 embedded in the communication between collective sender and recipient on level 2. On that second and superior level, the role of the ordinary recipient is further distinguished from that of the metarecipient, which is a term reserved for more analytical recipients, such as researchers. She explains the concept of metarecipient as follows:

This is an informed recipient who watches a film as if from a privileged position, analysing its discourse consciously and, frequently, making insightful observations about a meaning conveyed and methods employed to achieve this end in the collective sender's production layer. (Dynel 2011: 1633)

$5 \quad$ Hutchby (2006: 14) proposes the term distributed recipients to refer to the audience of broadcast talk, because it "seems to capture the sense in which the audience is addressed, albeit often indirectly, and situated as a ratified (though non-co-present) hearer rather than an eavesdropper". 


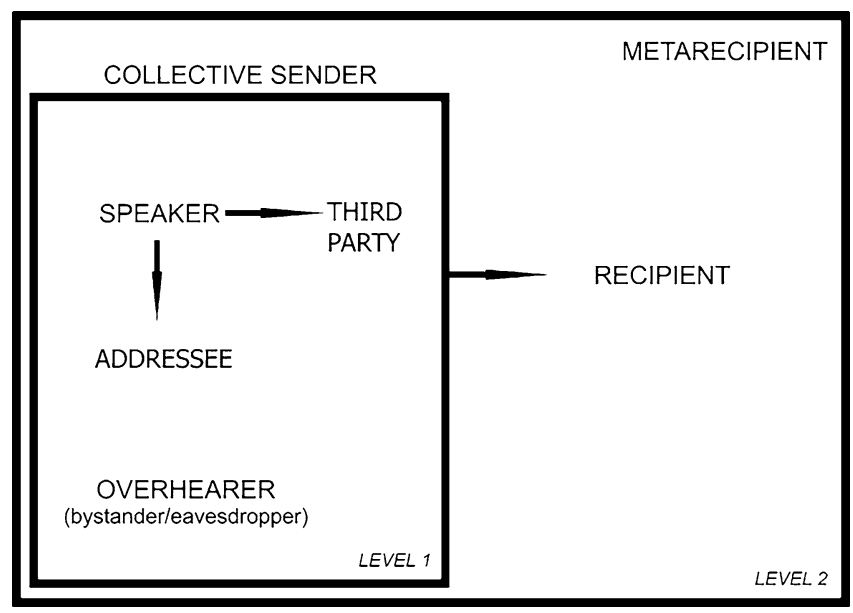

Figure 2. Participants in telecinematic discourse in Dynel (2011: 1634)

Contrary to the analytical metarecipient, Dynel repeatedly defines the ordinary recipient as immersed in the fiction and oblivious of its constructedness: "Normally, the viewer willingly forgets about the real production end and engages in characters' interactions" (Dynel 2011: 1632), and further: "The viewer normally assumes that there are no other authors of utterances than the characters, which is the essence of regular film watching" (Dynel 2011: 1632). Dynel attests that the rigid separation between recipients and metarecipients is done for methodological clarity, and she acknowledges that ordinary recipients may in fact share some of the analytical observations typically associated with metarecipients.

Dynel's distinction thus at least potentially marks two endpoints of a continuum between immersion and awareness of the artefact - or in Clark's (1996) and Bubel's $(2006,2008)$ terms between appreciation and imagination of the recipient. This is important because it points towards more attention in the theory towards individual differences in the audience. The metarecipient/recipient dichotomy is based on ideal viewer types rather than real viewers, but it can be read as a first step away from a universal audience. The cognitive processes that Bubel (2006, 2008) included into her framework can of course also be read as an acknowledgment of a diversified audience in which each individual viewer is influenced not only by the cues that are provided on the fictional layer, but also by their individual prior knowledge. Bubel $(2006,2008)$, however, speaks only of different processes on the part of the viewers, not of different viewer types or even individual viewers that would need to be distinguished.

With regard to the extract from Seinfeld (Example 1), distinguishing metarecipients and recipients will result in two different understandings of the scene. Ordinary recipients will follow the initially offered naïve interpretation of the 
scene as if George and Jerry were real people in a real coffee shop in New York. Taking the initial discussion about shirts as an example, the recipients may relate to or even identify with the process of having to choose a shirt in a store, they may agree or disagree with the notion that the position of the second button is important for selecting what shirt to buy, and they may make inferences about what kind of people George and Jerry may be. In other words, they will willingly suspend their disbelief and listen to the conversation as if it were taking place between two strangers or acquaintances. Metarecipients, on the other hand, will be aware of some of the ways in which linguistic and other means are employed for the construction of the scene. They may observe, for instance, how the actors perform their roles, that the topic being discussed is pronouncedly ordinary in the context of its representation in a fictional artefact, or how incongruities are constructed in the dialogue for humorous effect - in short, their viewing will be similar to the one offered here at the end of Section 3.1.

\subsection{Participation in Brock (2015)}

The last approach to telecinematic participation presented in this section is the one put forward by Brock (2015). It is important for a number of reasons: First of all, it addresses the overhearer/ratified participant difference in the role of film and television audiences and offers a view that combines both approaches. Secondly, it suggests a more explicitly dynamic model of recipientship than those of Bubel (2006, 2008) or Dynel (2011). Finally, it compares a range of different comedy genres and thus highlights important questions with regard to the universal applicability of fictional participation frameworks.

Brock's (2015) approach to participation in sitcoms and other comedies follows Dynel (2011) in its understanding of television audiences as ratified participants. Brock (2015: 28) refers to the audience as: "addressee and indeed the central and intended recipient of the communicative system of the TV discourse". He chooses the term $T V$ viewer instead of Dynel's recipient, but this is a mere terminological difference. He also subscribes to the same hierarchy of levels, and refers to the level between collective sender and TV viewer as Communicative Level 1 (CL1), which is "the primary and only real level of communication here" (Brock 2015: 29-30). Interaction between characters takes place on $C L 2$. Interestingly, however, Brock does not discard the viewer-as-overhearer notion as completely as Dynel (2011). Similar to Bednarek's (2010) mention of character and actor gestures being conflated on the speaker-side (see Section 3.2), Brock argues on the hearer-side that TV viewers can be in different roles at the same time. While they are always ratified addressees on CL1, they can be overhearers, but also speakers or addressees of individual characters on CL2.

In order to position TV viewers in a certain way, Brock (2015: 32) envisions that "a fictitious participation slot is constructed into the participation framework 
on CL2 in order to accommodate the viewer". The default camera position in the television comedies that Brock analyses resembles that of a person present in the scene, and the fictional characters conventionally ignore the presence of a camera altogether (Brock 2015: 32). As a result, the constructed participation slot "resembles the position of a natural overhearer and [...] becomes the main (fictitious) identification point for the real TV viewer to slip into" (Brock 2015: 32-33). The positioning of the viewer as a fictitious overhearer is thus considered a collaborative achievement by the collective sender, who prepares the slot, and the viewer, who plays along - just as viewers generally need to suspend their disbelief in order to engage with the fictional layer.

While the range of extracts discussed by Brock (2015) cannot be discussed here in full, it is worth mentioning that he provides convincing examples from less conventional comedies that construct a different fictitious participation slot. For instance, he shows how the British sitcom Peep Show (Channel 4 2003-2015) positions viewers as speakers and addressees of inter-character conversations: Using point-of-view shots, which are achieved by "strapping a camera to an actor's head or holding it before his/her face" (Brock 2015: 37), the sitcom aligns the perspective of the television viewer with that of the speaking or addressed character. Making use of voice-over at the same time, which may represent the respective character's thoughts or speech, the telecinematic apparatus invites the audience to become the fictional character (Brock 2015: 36) and to pretend to interact with the other characters as if they all shared the same fictional space. More generally, Brock's separation of viewer participation roles on CL1 and CL2 means that the viewers of the comedies he is interested in are in two roles at the same time. They need to be immersed in order to empathically follow the fictional story, but they also need to be akin to Dynel's (2011) metarecipients in order to laugh at the humour that is being constructed for them.

Returning to Example 1, we are overhearers insofar as we listen to Jerry and George's conversation without them acknowledging our presence, but we are also ratified participants who laugh about the humorous events that the writers and creators have conceived and that are realized in the actors' performances. The audience-as-ratified participant position is particularly salient in moments where the collective sender employs telecinematic means that go beyond the capturing of naturalistic actor-as-character performances. They range from the use of poetic language (Kozloff 2000: 51-52) to actors emphasizing their own performance (60-61), to voice-over narrating and directly addressing the audience. In the case of Seinfeld, examples are the blurring of the boundaries between fact and fiction, which is achieved by emphasizing the similarities between the fictional character and the actor portraying him, the prologue in which Jerry Seinfeld performs as a stand-up comedian (as described in Section 2.1), and the laugh track which forms part of the broadcast.

The duality of audience positions can be seen as reminiscent to the inherent 
contradiction in Bubel's $(2006,2008)$ concept of overhearer design, which makes the audience both overhearer and target of character interaction. However, explicitly foreseeing two participation roles for viewers on different communicative levels is an important addition by Brock, which will need to be explored further in future research. One question that immediately presents itself is whether this combination of viewer imagination and appreciation can be transferred to other film and television genres, or if it is a characteristic of comedies that they position their audiences in such a dual role. If the latter is the case, this would mean that other, more traditionally narrative genres could still follow the ideal of the immersed viewer, which Dynel (2011) assumes as the default.

A final methodological achievement in Brock's (2015) framework is the comparative position he takes with regard to participation, moving from different subtypes of television comedies to other comedy genres (stand-up comedies and candid camera comedies). The result of this approach is a range of different participation models and visualizations, which are all based on the same theoretical understanding as it was outlined here, but show a different participation configuration for each particular communicative setting.

\subsection{Summary}

This section has discussed four different theoretical approaches to the participation structures of telecinematic discourse in order to illuminate the communicative setting and the participant roles as they are described in different pragmatic frameworks. There is first of all a consensus that telecinematic and other fictional communication takes places on two separate levels or layers, which comprise the communication between the collective sender or film production crew and the television or film audience on one level, and the fictional interaction between characters on another. There is furthermore wide agreement that the communication on the fictional level is subject to overhearer or recipient design (the term used by Dynel 2011), i.e. that those conversations which take place in the seemingly self-contained fictional world are in fact written with a television or film audience in mind, and that viewers are meant to understand the meaning that is construed by the collective sender.

While the roles of participants on the fictional layer are straightforward and can be explained with the help of participation frameworks for non-fictional discourse, such as the one presented in Goffman (1979), there is some debate about the way in which the film or television audience has to be envisioned. Whereas the term overhearer is used by Bubel (2006, 2008), Bednarek (2010) and by a number of works in film studies (Kozloff 2000; Richardson 2010), Dynel (2011) argues that film audiences have to be understood as ratified participants or recipients. Brock (2015) combines both views with the help of the two different communicative levels: He regards audiences as ratified participants on the level between 
collective sender and real audiences, but suggests that on the fictional layer slots for different participation roles can be constructed, which the audience can then inhabit as part of their suspension of disbelief. While Brock gives examples for a range of different roles, he regards the role of overhearer as one of the typical slots that is opened for viewers. Thus viewers-as-overhearers and viewers-as-ratified participants both find their place in Brock's (2015) framework.

\section{Participation frameworks of literary fiction and dramatic discourse}

Given that Section 3 has outlined in some detail how fictional participation is understood in pragmatic research on telecinematic discourse, it will be the task of this section to complement the telecinematic frameworks with a brief look to other subcategories of fiction and to different research traditions and participation frameworks that, for the most part, precede the ones presented in the main section. I will first address playwrights and theatregoers and will then turn to participation in literary fiction.

\subsection{Participation and drama}

It has to be noted first of all that, due to the theoretical position from which telecinematic frameworks of participation describe collective sender, audience and characters, there is no reason why drama could not be included in the same models. In fact, despite the focus on telecinematic data, all presented frameworks can be said to implicitly serve as general models of fictional participation. While more recent participation models have shown more awareness for individual audience members and differences between genres, they still do not consider specific viewing situations and pay no heed, for instance, to how seeing a television show on a tablet or laptop might differ in terms of participation from seeing it together with other people at the cinema.

Traditional categorization based on the production and staging of the fictional interaction will say that film, television and drama are three distinct art forms. However, in terms of participation structures, seeing a film at a cinema shares some similarities with seeing a play that it does not share with seeing a film on one's own - most notably the fact that the action of viewing is in both cases shared with an audience. At the same time, there are of course differences between the staging of a play and television/film production, which are only of interest here, however, insofar as they influence participation structures and in particular the role of the audience.

Despite obvious similarities between drama and telecinematic discourse, most research on participation in fictional film and television has paid little attention to work on dramatic discourse. Herman (1995: 3) states, however, that there has tra- 
ditionally been very little research on dramatic dialogues, which may also explain the sparsity of references to dramatic participation.

Goffman discusses the conventions of the theatrical frame in some detail and includes notions such as the willing suspension of disbelief, which is expressed in the description "voluntarily supported benign fabrication" (1986: 136). His distinction between onlookers and theatregoers is worth mentioning here, because it implies a similar conflation of audience roles as it appears in Brock (2015). Goffman (1986: 130) uses laughter as an example and states that the onlooker is sympathetic and laughs about the staged humorous actions, whereas the theatregoer laughs about an unscripted blunder by the actor on stage. Onlooking, Goffman (1986: 131) adds, is similar in the case of reading and viewing a play, (and surely also in the case of viewing a television show or film), whereas the other role - in this case theatregoing - is markedly different.

With regard to the role of the audience, Goffman (1986: 141) also states that their response "is systematically built into the interaction on stage". He adds: "the audience is given the information it needs covertly, so the fiction can be sustained that it has indeed entered into a world not its own" (Goffman 1986: 142). Thus he includes the notion of fiction being designed for an audience as well as that of the playwright making particular information available to audiences, while still maintaining the illusion.

Herman (1995: 29) speaks of the "double axes of character-character interaction and stage-audience reception" and includes similar aspects of audience design or information management on the production-side. That is, some of the information that is provided may be of more interest to either the characters on stage or the audience, and differences in knowledge between the two may be used for specific effect, such as dramatic irony (Herman 1995: 29-30).

The most complex pragmatic model for dramatic discourse, both as communication mediated through the written text and through the performed play, is the one presented by Hess-Lüttich (1991). He understands dramatic communication as aesthetic communication, which embeds character dialogues in public communication (1991: 234). Text and performed play also incorporate the implied author and the fictive reader/anticipated audience, which means that their relationship is accessible in the text.

It seems, however, that within linguistics the participation framework in Short $(1981,1989)$ is still the framework most widely cited, both in research on dramatic and telecinematic discourse. Short (1981) was already mentioned in Section 2 as an example for a theory that envisions character interactions as embedded in the communication between audiences and, in this case, the playwright and others who are involved in the writing and staging of theatre. Short offers a model that, considered within the anachronistic order that his chapter follows, can be read as a predecessor of telecinematic frameworks. He envisions dramatic communication on two levels, with the playwright sending a message to the audience on one level, and charac- 
ters sending and receiving messages on the other (Short 1981: 188). The discourse between characters is embedded into the dramatic discourse and becomes part of the message from the playwright to the audience. Short refers to the audience as the main addressee and refutes the notion that they could be overhearers.

Drama as performance can thus be understood as similar in participation to film and television viewing. As long as individual reception settings are not differentiated in detail, there is no reason why pragmatic research cannot devise a unified participation framework that can explain both the participant roles in telecinematic and in dramatic fiction. Drama as text, i.e. reading plays, or screenplays for that matter, will be treated here as part of literary fiction. As Short (1981: 182) states, theatrical criticism needs to address performance, whereas the text can be analysed within literary criticism.

\subsection{Participation and literary fiction}

Participation frameworks in telecinematic discourse and theatrical performance are rooted for the most part in pragmatic theories of participation developed for face-to-face interaction and more generally spoken interaction. Author, reader and character roles in literary fiction, in contrast, have been theorized in literary criticism, stylistics and more recently in literary pragmatics. On the one hand, it can be said that the foundations for later work on literature as communication were already laid in early literary criticism; on the other hand, it has to be pointed out that an interest in readers is relatively recent, and for the most part can be traced back to reader response criticism in the 1960s and 1970s.

Whereas the earlier paradigms of formalism and New Criticism focused on the text (Riddle Harding 2014: 68), reader response criticism shifted that focus to include the role of the readers. As Peplow and Carter (2014) point out, much of the ensuing work was, however, primarily interested in idealized or implied readers, which is Iser's (1972) equivalent on the side of the reader to Booth's (1961) famous notion of the implied author. The implied reader is a construct in the text and has been described as: "a reader who has the necessary linguistic and cultural knowledge to understand and appreciate the text" (Black 2006: 54). The literary work, in other words, is written with an ideal reader in mind, which is a notion quite similar to that of recipient or overhearer design as it is taken up by all telecinematic frameworks presented in Section 3. In the same section, it has also been mentioned that telecinematic discourse is only slowly turning towards a more detailed look at different audiences or even individual audience members. There is thus a similarity in the conceptualization of the audience, which in both approaches is potentially diverse, but treated in the actual theory as a homogenous whole.

As Riddle Harding (2014) points out, the interest of reader response criticism in readers has later been taken up by many different subdisciplines of literary theory and criticism. Among others, she mentions different cognitive approaches 
to reading, which focus quite literally on the cognitive processes involved when engaging with a literary text, more sociological approaches such as gender studies, reception studies, and empirical reading studies that focus on actual readers and their responses to literary works (Riddle Harding 2014). Riddle Harding (2014: 79) herself defines the process of reading as follows: "Reading [...] is a creative process in which a reader detects textual cues by engaging actively with the text". This is a stance very similar to that of Dynel's (2011: 1633) active recipientship, which positions audiences as active viewers of films and television shows, but Riddle Harding here also emphasizes the individual creativity required of the reader.

Most relevant for this discussion of literary participation is the work of Sell $(1991,2000,2001,2014)$ and the Literary Communication Project of Åbo Akademi University. Sell (2014: 3) programmatically states that he and the LitCom group regard "writing, reading and performance of so-called literary texts as acts of real communication between real human beings as they engage in what is fundamentally a kind of dialogue". More specifically, Sell positions himself between the structuralist view of literary texts as products of their socio-cultural context and a subjectivist notion of authors and readers as idiosyncratic individuals. He sees human beings as social individuals that possess both their own imagination, but are also influenced by historical factors (Sell 2000, 2014). This understanding of authors and readers is also expressed in his theory of a historical yet non-historicist literary pragmatics (Sell 2000), which also highlights the necessity of a mediating critic that bridges the gap between the socio-historical context of the author and that of the reader.

Sell (2000: 2) adheres to a basic triangular understanding of literary communication, which is to say that author and reader are communicating about the literary work as a third entity. This is not different in principle from the telecinematic frameworks by Bubel $(2006,2008)$ and Dynel $(2011)$, but the latter two explain in more detail the intrinsic structure of the fictional third entity and the processes that lead to its production and comprehension. One crucial difference between literature and film is of course that the latter is inevitably a product of multiple authors, i.e. the collective sender, and often received by an audience rather than by an individual. Literary fiction, on the contrary, is prototypically written by one author and read by one reader. Perhaps due to this difference, Sell (2000) and literary pragmatics more generally base their understanding of fictional participation more directly on a dyadic model of dialogue. That Sell's notion of the mediating critic has the semblance of a translator between two interlocutors from different sociocultural backgrounds may be explained by this difference.

However, such differences in focus aside, Sell's communicative understanding of literature is quite similar to recent pragmatic understandings of participation in telecinematic discourse, and his notion of reading as an active part of communication (Sell 2000: 72) is in accordance with both Riddle Harding's (2014) creative reading process and Dynel's (2011) active recipients. 


\section{Future directions and concluding remarks}

One of the issues raised in the introduction of this chapter is the lack of substantial theoretical work that would offer a participation framework for different subtypes of fictional discourse. Given the fact that research on participation in telecinematic discourse explicitly or implicitly draws on previous work from drama and from literary fiction, and taking into account the similarity in production and reception processes between the different fictional genres, such a unified theory of participation in fiction would prove a fruitful addition to pragmatic research. Accordingly, this chapter has focused on commonalities between participation in different forms of fictional discourse. The clear focus here has been on telecinematic frameworks, and theoretical observations from dramatic discourse and literary pragmatics and stylistics have retrospectively been identified as predecessors of more recent participation frameworks.

In terms of the future directions of the field, a trend towards a more finegrained look at film and television viewers and by extension at theatregoers and readers has been suggested. It seems plausible based on current trends that future research will produce conceptualizations of participation structures that pay more heed to differences between recipients, but also between different genres and subtypes of fiction. This expected diversification is not to be understood as antithetical to a unified theory of fictional participation - Brock (2015), for instance, shows nicely how juxtaposing different participation settings under one unifying theoretical approach can be a productive way of highlighting both commonalities and differences in various kinds of fictional communications.

This chapter has followed the research it presents in focussing on the recipient's point of view. The production processes that are included in the different frameworks are invariably removed from the actual production and placed instead inside the communication between text and reader, as part of what can be detected or inferred by metarecipients but may not be noticed by ordinary recipients. This recipient bias raises the question, however, whether communication between author and text deserves more weight in pragmatic research. Especially in telecinematic discourse, real viewer research, in analogy to real reader research in literary pragmatics, could be complemented by real production crew research. While current frameworks at best make assumptions about how fictional artefacts might have been created, the collaborative construction of meaning between scriptwriters, directors, but also the cast and crew of films and fictional television is taking place within a different type of communicative setting altogether. A pragmatics of fiction production would then need to shift its attention from the artefact as a finished fictional product to the elaborate joint processes that lead to its existence: Instead of recipient design, for instance, it would examine recipient designing. 


\section{Appendix. Transcription conventions}

(based on Jefferson 2004; Mondada 2014)

[ ] overlapping speech

(.) short gap between utterances

$=\quad$ latch

- stress

: indicates lengthening of the previous sound

$\uparrow \downarrow \quad$ shift to high or low pitch

., ?! punctuation indicates usual intonation

$* \pm \S^{\wedge} \quad$ symbols to identify participants

*---_* delimits action/facial expression by participant

*----> action continues on subsequent line(s)

----* action ends

34 numbers in left-hand column refer to camera shots

\section{References}

Primary sources

Peep Show

2003-2015 Screenplay by Martin Becky, Tristam Shapeero and Jeremy Wooding, Channel 4.

The Seinfeld Chronicles

1989 Dir. Art Wolff. Screenplay by Larry David and Jerry Seinfeld. NBC.

Gilmore Girls

2000-2007 Screenplay by Amy Sherman-Palladino. The WB Television Network.

\section{Secondary sources}

Androutsopoulos, Jannis

2012 Introduction: Language and society in cinematic discourse. Multilingua 31(2-3): 139-154.

Bednarek, Monika

2010 The Language of Fictional Television: Drama and Identity. London: Continuum.

Bednarek, Monika

2012 "Get us the hell out of here": Key words and trigrams in fictional television series. International Journal of Corpus Linguistics 17(1): 35-63.

Black, Elizabeth

2006 Pragmatic Stylistics. Edinburgh: Edinburgh University Press.

Booth, Wayne C.

1961 The Rhetoric of Fiction. Chicago, IL: University of Chicago Press. 
Brock, Alexander

2009 Humour as a metacommunicative process. Journal of Literary Theory 3(2): 177-193.

Brock, Alexander

2015 Participation frameworks and participation in televised sitcom, candid camera and stand-up comedy. In: Marta Dynel and Jan Chovanec (eds.), Participation in Public and Social Media Interactions, 27-47. Amsterdam/Philadelphia:

Bubel, Claudia M. John Benjamins.

2006 The Linguistic Construction of Character Relations in TV Drama: Doing Friendship in Sex and the City. Universität des Saarlandes. http://scidok.sulb.

Bubel, Claudia M. uni-saarland.de/volltexte/2006/598/pdf/Diss_Bubel_publ.pdf

2008 Film audiences as overhearers. Journal of Pragmatics 40(1): 55-71.

Burger, Harald

1984 Sprache der Massenmedien. Berlin: Walter de Gruyter.

Burger, Harald

1991 Das Gespräch in den Massenmedien. Berlin: Walter de Gruyter.

Burger, Harald and Martin Luginbühl

2014 Mediensprache: Eine Einführung in Sprache und Kommunikationsformen der Massenmedien, $4^{\text {th }}$ Ed. Berlin: Walter de Gruyter.

Chovanec, Jan and Marta Dynel

2015 Researching interactional forms and participant structures in public and social media. In: Marta Dynel and Jan Chovanec (eds.), Participation in Public and

Clark, Herbert H.

Social Media Interactions, 1-23. Amsterdam/Philadelphia: John Benjamins.

1996 Using Language. Cambridge, UK: Cambridge University Press.

Clark, Herbert H. and Edward F. Schaefer

1992 Dealing with overhearers. In: Herbert H. Clark (ed.), Arenas of Language Use, 248-273. Chicago, IL: University of Chicago Press.

Culpeper, Jonathan

2001 Language and Characterisation: People in Plays and Other Texts. Harlow: Longman.

Desilla, Louisa

2012 Implicatures in film: Construal and functions in Bridget Jones romantic comedies. Journal of Pragmatics 44(1): 30-53.

Dynel, Marta

2011 "You talking to me?" The viewer as a ratified listener to film discourse. Journal of Pragmatics 43(6): 1628-1644.

Goffman, Erving

1967 Interaction Ritual. Essays on Face-to-Face Behavior. New York: Anchor Books.

Goffman, Erving

1976 Replies and responses. Language in Society 5(3): 257-313. http://www.cambridge.org/about-us/who-we-are/history/

Goffman, Erving

1979 Footing. Semiotica 25(1-2): 1-29. 
Goffman, Erving

1986 Frame Analysis: An Essay on the Organization of Experience. Boston, MA: Northeastern University Press. First published Cambridge, MA: Harvard Uni-

Hall, Stuart versity Press [1974].

1994 Encoding/decoding. In: David Graddol and Oliver Boyd-Barrett (eds.), Media Texts: Authors and Readers, 200-211. Clevedon, UK: Multilingual Matters.

Herman, Vimala

1995 Dramatic Discourse: Dialogue as Interaction in Plays. New York: Routledge. Hess-Lüttich, Ernest W. B.

1991 How does the writer of a dramatic text interact with his audiences?: On the pragmatics of literary communication. In: Roger D. Sell (ed.), Literary Pragmatics, 225-259. New York: Routledge.

Hutchby, Ian

2006 Media Talk: Conversation Analysis and the Study of Broadcasting. Maidenhead: Open University Press.

Iser, Wolfgang

1972 Der implizite Leser. München: Wilhelm Fink Verlag.

Jefferson, Gail

2004 Glossary of transcript symbols with an introduction. In: Gene H. Lerner (ed.), Conversation Analysis: Studies from the First Generation, 13-31. Amsterdam/ Philadelphia: John Benjamins. http://www.liso.ucsb.edu/liso archives/Jeffer-

Kozloff, Sarah son/Transcript.pdf

2000 Overhearing Film Dialogue. Berkeley, CA: University of California Press. Mondada, Lorenza

2014 Conventions for multimodal transcription. https://franz.unibas.ch/fileadmin/ franz/user_upload/redaktion/Mondada_conv_multimodality.pdf

Peplow, David and Ronald Carter

2014 Stylistics and real readers. In: Michael Burke (ed.), The Routledge Handbook of Stylistics, 440-454. Oxon: Routledge.

Piazza, Roberta, Monika Bednarek and Fabio Rossi

2011 Introduction: Analysing telecinematic discourse. In: Roberta Piazza, Monika Bednarek and Fabio Rossi (eds.), Telecinematic Discourse: Approaches to the Language of Films and Television Series, 1-17. Amsterdam/Philadelphia: John Benjamins.

Richardson, Kay

2010 Television Dramatic Dialogue: A Sociolinguistic Study. Oxford, UK: Oxford University Press.

Riddle Harding, Jennifer

2014 Reader response criticism and stylistics. In: Michael Burke (ed.), The Routledge Handbook of Stylistics, 68-84. Oxon, UK: Routledge.

Sacks, Harvey, Emanuel A. Schegloff and Gail Jefferson

1974 A simplest systematics for the organization of turn-taking for conversation. Language 50(4/1): 696-735.

Sell, Roger D.

1991 The politeness of literary texts. In: Roger D. Sell (ed.), Literary Pragmatics, 208-241. New York: Routledge. 
Sell, Roger D.

2000 Literature as Communication: The Foundations of Mediating Criticism. Amsterdam/Philadelphia: John Benjamins.

Sell, Roger D.

2001 A historical but non-determinist pragmatics of literary communication. Journal of Historical Pragmatics 2(1): 1-32. http://www.redi-bw.de/db/ ebsco.php/search.ebscohost.com/login.aspx?direct $=$ true $\& \mathrm{db}=$ mzh \&AN

Sell, Roger D. $=2001931532 \&$ site $=$ ehost-live $\&$ scope $=$ cite

2014 Introduction. In: Roger D. Sell (Ed.), Literature as Dialogue: Invitations Offered and Negotiated, 1-20. Amsterdam/Philadelphia: John Benjamins.

Short, Mick H.

1981 Discourse analysis and the analysis of drama. Applied Linguistics 2(2): 180201.

Short, Mick H.

1989 Discourse analysis and the analysis of drama. In: Ronald Carter and Paul Simpson (eds.), Language, Discourse and Literature: An Introductory Reader in Discourse Stylistics, 139-168. London: Unwin Hyman.

Vanoye, Francis

1985 Conversations publiques. IRIS: A Journal of Theory on Image and Sound 3(1): 99-188. 